\title{
Hyperuricaemia in Cardiovascular Diseases: A Passive or an Active Player?
}

\author{
Niki Katsiki $^{a} \quad$ Dimitri P. Mikhailidis ${ }^{b}$ \\ a Second Propedeutic Department of Internal Medicine, Medical School, Aristotle University of Thessaloniki, \\ Hippocrates Hospital, Thessaloniki, Greece; ${ }^{b}$ Department of Clinical Biochemistry (Vascular Disease Prevention \\ Clinics), Royal Free Hospital Campus, University College London Medical School, University College London (UCL), \\ London, UK
}

In this issue of Medical Principles and Practice, Celik et al. [1] reported an independent negative correlation between serum uric acid (SUA) levels and blood flow velocity of the left atrial appendage (LAA) in 153 patients with atrial fibrillation (AF). Multivariate regression analysis showed that male gender $(p \leq 0.001)$, age $(p=0.009)$ and SUA levels $(\mathrm{p}=0.010)$ were independent predictors of the LAA peak flow velocity [1]. The clinical implication of a low LAA flow velocity was based on its association with an increased risk of thromboembolism. Therefore, elevated SUA concentrations may also be linked to an increased thromboembolic risk, as shown in a recent study [2].

Celik et al. [1] mentioned the relationship between increased SUA levels and AF, a finding that was supported by a recent meta-analysis [3]. Furthermore, hyperuricaemia had been shown to predict stroke incidence in AF patients [4]. Elevated SUA levels have also been associated with increased cardiovascular (CV) morbidity and mortality, as Celik et al. [1] stated. Patients with carotid atherosclerosis and peripheral artery disease may also have increased SUA concentrations compared with controls [5]. Furthermore, several CV risk factors including dyslipidaemia, diabetes, obesity, hypertension, metabolic syndrome, non-alcoholic fatty liver disease and kidney

\begin{tabular}{ll}
\hline KARGER 125/s & $\begin{array}{l}\text { ( } 2015 \text { S. Karger AG, Basel } \\
1011-7571 / 15 / 0243-0269 \$ 39.50 / 0\end{array}$ \\
$\begin{array}{l}\text { E-Mail karger@karger.com } \\
\text { www.karger.com/mpp }\end{array}$ & $\begin{array}{l}\text { This is an Open Access article licensed under the terms of the } \\
\text { Creative Commons Attribution-NonCommercial 3.0 Un- } \\
\text { ported license (CC BY-NC) (www.karger.com/OA-license), } \\
\text { applicable to the online version of the article only. Distribu- } \\
\text { tion permitted for non-commercial purposes only. }\end{array}$
\end{tabular}

dysfunction have been related to hyperuricaemia $[5,6]$. In diabetic patients, elevated SUA levels were linked to both micro- and macrovascular complications [7]. These associations confound the relationship of SUA with CV risk, making it difficult to isolate the contribution of SUA. Large numbers of individuals are needed to help compensate for this limitation, using multivariate analyses or selecting very specific patient groups (e.g. by gender, age and obesity) to decrease heterogeneity.

A key question is whether lowering of SUA decreases the risk of CV. In this context, allopurinol and febuxostat (both inhibitors of xanthine oxidase) have been reported to improve CV outcomes [8], although the data are limited and further research is needed. Several drugs that may reduce CV risk were also shown to decrease SUA levels (e.g. captopril, enalapril, ramipril, losartan and amlodipine, metformin, pioglitazone, atorvastatin, simvastatin, ezetimibe and fenofibrate) $[5,7]$. These effects may not be widely known, and their contribution to additional risk reduction is not clear, as the data are limited. More importantly, in the Losartan Intervention for Endpoint Reduction in Hypertension (LIFE) trial [9] and the Greek Atorvastatin and Coronary-Heart Disease Evaluation (GREACE) study [10], the drug-induced SUA-lowering effect was reported to contribute to $\mathrm{CV}$ risk reduc- 
tion. In the LIFE trial [9], elevated SUA concentrations significantly correlated with an increased risk of CV events [hazard ratio (HR) 1.024, 95\% confidence interval (CI) $1.017-1.032$ for every $10 \mu \mathrm{mol} / \mathrm{l}, \mathrm{p}<0.0001$ ] in the entire study population. With regard to gender differences, this association was significant only in women (HR 1.025, 95\% CI 1.013-1.037, p < 0.0001). In the GREACE study [10], the HR for coronary heart diseaserelated events was 0.89 (95\% CI 0.78-0.96, $\mathrm{p}=0.03)$ for every $0.5-\mathrm{mg}(30 \mu \mathrm{mol} / \mathrm{l})$ reduction in SUA levels and $0.76(95 \%$ CI $0.62-0.89, \mathrm{p}=0.001)$ for every $1-\mathrm{mg}(60$ $\mu \mathrm{mol} / \mathrm{l})$ reduction. In contrast, the HR was 1.14 (95\% CI 1.03-1.27, $\mathrm{p}=0.02)$ with every 0.5 -mg increase in SUA levels and 1.29 (95\% CI 1.17-1.43, $\mathrm{p}=0.001)$ with every 1 -mg increase [10].
In conclusion, hyperuricaemia seems to be independently associated with CV diseases, resulting in increased morbidity and mortality. SUA-lowering drugs may ameliorate CV risk, and certain drugs used to prevent CV disease may decrease SUA levels as an added action. Further large prospective studies are needed to establish the role of SUA in daily clinical practice.

\section{Disclosure Statement}

None. However, it is important to point out that this commentary was written independently. The authors did not receive financial or professional help with the preparation of the manuscript. The authors have given talks, attended conferences and participated in trials sponsored by various pharmaceutical companies.

\section{References}

1 Celik M, Yalcinkaya E, Yuksel UC, Gokoglan Y, Bugan B, Kabul HK, Barcin C: Increased serum uric acid levels are correlated with decreased left atrial appendage peak flow velocity in patients with atrial fibrillation. Med Princ Pract DOI:10.1159/000373892.

$\checkmark 2$ Numa S, Hirai T, Nakagawa K, et al: Hyperuricemia and transesophageal echocardiographic thromboembolic risk in patients with atrial fibrillation at clinically low-intermediate risk. Circ J 2014;78:1600-1605.

3 Tamariz L, Hernandez F, Bush A, et al: Association between serum uric acid and atrial fibrillation: a systematic review and meta-analysis. Heart Rhythm 2014;11:1102-1108.
4 Chao TF, Liu CJ, Chen SJ, et al: Hyperuricemia and the risk of ischemic stroke in patients with atrial fibrillation - could it refine clinical risk stratification in AF? Int J Cardiol 2014; 170:344-349.

5 Katsiki N, Karagiannis A, Athyros VG, et al: Hyperuricaemia: more than just a cause of gout? J Cardiovasc Med (Hagerstown) 2013; 14:397-402.

-6 Katsiki N, Athyros VG, Karagiannis A, et al: Hyperuricaemia and non-alcoholic fatty liver disease (NAFLD): a relationship with implications for vascular risk? Curr Vasc Pharmacol 2011;9:698-705.

7 Katsiki N, Papanas N, Fonseca VA, et al: Uric acid and diabetes: is there a link? Curr Pharm Des 2013;19:4930-4937.
8 Agabiti-Rosei E, Grassi G: Beyond gout: uric acid and cardiovascular diseases. Curr Med Res Opin 2013;29(suppl 3):33-39.

$\checkmark 9$ Høieggen A, Alderman MH, Kjeldsen SE, et al; LIFE Study Group: The impact of serum uric acid on cardiovascular outcomes in the LIFE study. Kidney Int 2004;65:1041-1049.

10 Athyros VG, Elisaf M, Papageorgiou AA, et al; GREACE Study Collaborative Group: Effect of statins versus untreated dyslipidemia on serum uric acid levels in patients with coronary heart disease. A subgroup analysis of the GREek Atorvastatin and Coronary-heart-disease Evaluation (GREACE) study. Am J Kidney Dis 2004;43:589-599. 